\title{
Levantamentos Geodésicos: Posicionamento por Ponto Preciso (PPP) e Transporte de Pontos da Rede Geodésica do Estado do Rio Grande do Sul - Determinação da Diferença Linear nas Coordenadas
}

\section{Geodetic Surveys: Precise Point Positioning (PPP) and Transportation of Points of the Geodetic Network of the State of Rio Grande do Sul - Determination of the Linear Difference in Coordinates}

\author{
DOI: $10.46814 / \operatorname{lajdv3n1-044}$
}

Recebimento dos originais: 30/10/2020

Aceitação para publicação: 23/12/2020

\section{Jeferson Silva De Sá}

Arquiteto e Urbanista graduado pela Universidade Regional Integrada do Alto Uruguai e Das Missões - URI Campus de Santiago (2016), tendo atuado como estagiário no Laboratório de Topografia da Uri (2013 - 2015), Pós Graduando em Engenharia de Segurança do Trabalho pela Cruzeiro do Sul Virtual (2020). Atua diretamente, como profissional liberal, na área de arquitetura e interiores, com projetos e execução de obras. Áreas de interesse: Projeto de Arquitetura,

Planejamento Urbano, Paisagismo, Projeto Arquitetônico de Cunho Sustentável, Arquitetura de Interiores, Design de Móveis.

Endereço: Rua Tito Livio Zambecare, No 503, Bairro: Mont'Serrat - Porto Alegre - Rs E-mail: arq.jefersondesa@gmail.com

Attus Pereira Moreira (In memoriam)

Possui graduação em Engenharia Civil pela Universidade Federal de Santa Maria(1980), graduação em Esquema 1 pela Universidade Federal de Santa Maria(1981), graduação em Estudos Sociais pela Faculdade de Filosofia Ciências e Letras de Alegrete(1974), especialização em Especialização em Processo Educacional pela Universidade Federal de Santa Maria(1984), mestrado em Engenharia Agrícola pela Universidade Federal de Santa Maria(1995) e doutorado em Engenharia de Transportes pela Universidade de São Paulo(1998). Atualmente é professor titular da Universidade Regional

Integrada do Alto Uruguai e das Missões. Tem experiência na área de Engenharia Civil, com ênfase em Construção Civil. Atuando principalmente nos seguintes temas:Coordenadas Tridimensionais, Engenharia.

Instituição: Atuava como professor titular da Universidade Regional Integrada do Alto Uruguai e das

$$
\text { Missões - URI SANTIAGO - RS }
$$

Endereço: Universidade Regional Integrada do Alto Uruguai e das Missões, Departamento de Ciências Sociais e Aplicadas. Av. Batista Bonotto Sobrinho, s/n, Centro 97700-000 - Santiago, RS Brasil

E-mail: attus@urisantiago.br

\section{RESUMO}

A falta de técnicos habilitados, disponíveis no mercado de trabalho, para as atividades de georreferenciamento e certificação de imóveis rurais, exige uma intervenção urgente das universidades, responsáveis pela formação, desta modalidade de conhecimento.

O projeto tem como objetivo verificar, em cinco repetições sucessivas, a diferença linear e precisão na obtenção das coordenadas (E,N), UTM SIRGAS/2000, para um ponto fixo, implantado no Campus da URI - Santiago. Para os cálculos das coordenadas obtidas pelo processo do posicionamento por Ponto Preciso (PPP), foram utilizadas, como estação base fixa, durante os cinco processos de rastreio, os dados do rastreio do marco da URI Campus Santiago e da Base de Alegrete, RS, obtidos via Internet. 
Para o marco de Santiago, na tomada de dados, empregou-se receptor GNSS fixo, de dupla frequência e, para a base de Alegrete, foram utilizados os dados captados via Internet, no formato de arquivo RINEX, conforme disponibilizado para todas as estações bases da rede geodésica brasileira. Foram executadas cinco seções de observações geodésicas, com o emprego de um receptor GNSS, Leica Viva GS15. Durante as leituras, o receptor base permaneceu instalado sobre o marco geodésico da Campus da URI Santiago, em modo estático e a antena receptora procedeu o rastreio do marco de apoio, no mesmo modo de rastreio.

As coordenadas geográficas obtidas pelos dois processos de rastreio serão transformadas em coordenadas geodésicas UTM SIRGAS/2000, bem como serão calculadas as diferença linear entre elas e analisados os comportamentos destas diferenças. Por fim, serão comparadas as médias das diferenças, caso haja, em cada método proposto.

Palavras-chave: georreferenciamento, posicionamento por Ponto Preciso, coordenadas geodésicas, coordenadas geográficas, diferença linear.

\section{INTRODUÇÃO}

A falta de técnicos habilitados, disponíveis no mercado de trabalho, para as atividades de georreferenciamento e certificação de imóveis rurais, exige uma intervenção urgente das Universidades, responsáveis pela formação, em nível superior, desta modalidade de conhecimento.

A complexidade das ações governamentais intervenientes no sistema fundiário nacional exigem altíssima qualificação técnica e familiarização com as tecnologias de ponta, principalmente sobre o Sistema Global de Navegação por Satélites.

O georreferenciamento de imóveis rurais é atribuição de várias categorias profissionais, dentre elas a Agronomia; e, o currículo do curso da URI Câmpus Santiago contempla este requisito, já certificado como atribuição pelo CREA/RS e referendado pelo INCRA, para nossos egressos.

Considerando avanços nas técnicas de Posicionamento por Ponto Preciso, onde as coordenadas dos vértices de interesse são determinadas de forma absoluta, portanto, dispensa o uso de receptor instalado sobre um vértice de coordenadas conhecidas; e, que o IBGE disponibiliza um serviço online de Posicionamento por Ponto Preciso (PPP), que processa dados no modo estático e cinemático em http://www.ppp.ibge.gov.br/ppp.htm, devemos preparar nossos alunos para enfrentar tais desafios.

\subsection{DEFINIÇÃO DO PROBLEMA}

No Posicionamento por Ponto utiliza-se um único receptor GPS. Este método de posicionamento tem sido muito empregado na navegação de baixa precisão e levantamentos expeditos. No entanto, o posicionamento instantâneo de um ponto, isto é, em tempo real, usando-se a pseudodistância derivada do código C/A presente na portadora L1, apresentava até o dia $1^{\circ}$ de maio 
de 2000, precisão planimétrica melhor que 100 metros, 95\% do tempo, por esse motivo não pode ser utilizado para o levantamento de pontos de apoio.

Mesmo se a coleta de dados, sobre um ponto estacionário, fosse de longa duração, a qualidade dos dados não melhoraria de modo significativo, em razão dos vários erros sistemáticos envolvidos na observável utilizada. Com a eliminação da Disponibilidade Seletiva (AS), à Oh (hora de Washington, Estados Unidos) do dia 02.05.00, a qualidade citada anteriormente melhorou em torno de 10 vezes. Isto já foi demonstrado em GALERA, 2005, observando-se através do estudo da dispersão de dois posicionamentos, antes e depois da eliminação do AS, mesmo assim não satisfaz as necessidades dos georrefenciadores.

A afirmação de que o PPP apresenta grande potencialidade para ser usado também em aplicações de geodinâmica (MONICO, 2008), com enormes vantagens sobre o processamento de redes GNSS, pois em tais redes há um grande dispêndio computacional, já nos induz a uma verificação prática.

Por sua vez, o transporte de Pontos da Rede Geodésica do Estado do Rio Grande do Sul, ou de outro ponto já homologado pelo IBGE, vem sendo utilizado desde o início, isto é, desde a divulgação da tecnologia GPS; e, está amplamente divulgado pela bibliografia (Segantine, 2005 e Galera, 2008).

O Laboratório de Geodésia e Topografia da URI Câmpus de Santiago, através de três convênios realizados com a Secretaria de Ciência e Tecnologia do Estado do Rio Grande do Sul, adquiriu equipamentos de última geração, para o posicionamento pelo GNSS.

Com vistas no treinamento de seus quadros de professores, funcionários e alunos dos cursos de Agronomia e Arquitetura e Urbanismo, estamos propondo pesquisas nesta área. Investir em pesquisa na área tecnológica, atualmente, em nosso país, para as Universidades Comunitárias como a nossa, não é só cumprir determinações do MEC, mas cooperar, de forma significativa, para aspirações de desenvolvimento. De outra forma, terminaremos importando profissional destas áreas, de competência, no mínimo duvidosa, como já tem demonstrado exemplos práticos.

\subsection{OBJETIVOS}

Diante do exposto, o presente projeto tem como objetivo verificar, em 5 (cinco) repetições sucessivas, realizadas em diferentes datas, com diferentes distribuições das constelações de satélites GPS e GLONASS, através do transporte das coordenadas do Marco Geodésico do IBGE do Câmpus da URI Santiago, com o Equipamento Geodésico (L1/L2), marca e modelo Leica Viva GS15 e processamento via serviço de Posicionamento por Ponto Preciso, pelo IBGE e ajustamento através do software Leica Geo Ofice, versão 8.3, para estabelecer a diferença linear e precisão na obtenção das 
coordenadas (E,N), UTM SIRGAS/2000, para um ponto fixo, implantado no Câmpus, através das duas modalidades de posicionamento propostas.

- Transformar as coordenadas geográficas obtidas pelos dois processos de rastreio em coordenadas geodésicas UTM SIRGAS/2000 e calcular a diferença linear entre elas;

- Analisar o comportamento das diferenças e comparar as médias das diferenças, caso haja, em cada método proposto;

- Preparar os bolsistas/estagiários para a execução de levantamentos, com vistas ao georreferenciamento e certificação de imóveis rurais.

\section{RESULTADOS E DISCUSSÕES}

\subsection{SESSÕES DE LEITURAS}

Foram executadas cinco seções de observações geodésicas, com o emprego de um receptor GNSS, marca e modelo Leica Viva GS15. Durante as leituras o receptor base permaneceu instalado sobre o marco geodésico da Rede Estadual, implantada pelo IBGE, no Câmpus da URI Santiago (Figura 1), em modo estático; e, a antena receptora procedeu o rastreio do marco de apoio (Figura 2), no mesmo modo de rastreio.

A tabela 1 mostra data e duração de cada sessão de leituras no modo estático sobre o marco de apoio.

Tabela 1: Demonstrativo da data e duração das sessões de leituras.

\begin{tabular}{ccc}
\hline \multicolumn{3}{c}{ Sessões de Leituras } \\
\hline Sessões & Data & Duração \\
\hline 1 & $15 / 12 / 2014$ & $04 \mathrm{~h} 38^{\prime} 51^{\prime \prime}$ \\
\hline 2 & $02 / 03 / 2015$ & $02 \mathrm{~h}^{\prime} 6^{\prime} 09^{\prime \prime}$ \\
\hline 3 & $04 / 03 / 2015$ & $01 \mathrm{~h} 39^{\prime} 16^{\prime \prime}$ \\
\hline 4 & $09 / 03 / 2015$ & $02 \mathrm{~h} 34^{\prime} 30^{\prime \prime}$ \\
\hline 5 & $23 / 03 / 2015$ & $01 \mathrm{~h}^{\prime} 44^{\prime} 02^{\prime \prime}$ \\
\hline
\end{tabular}




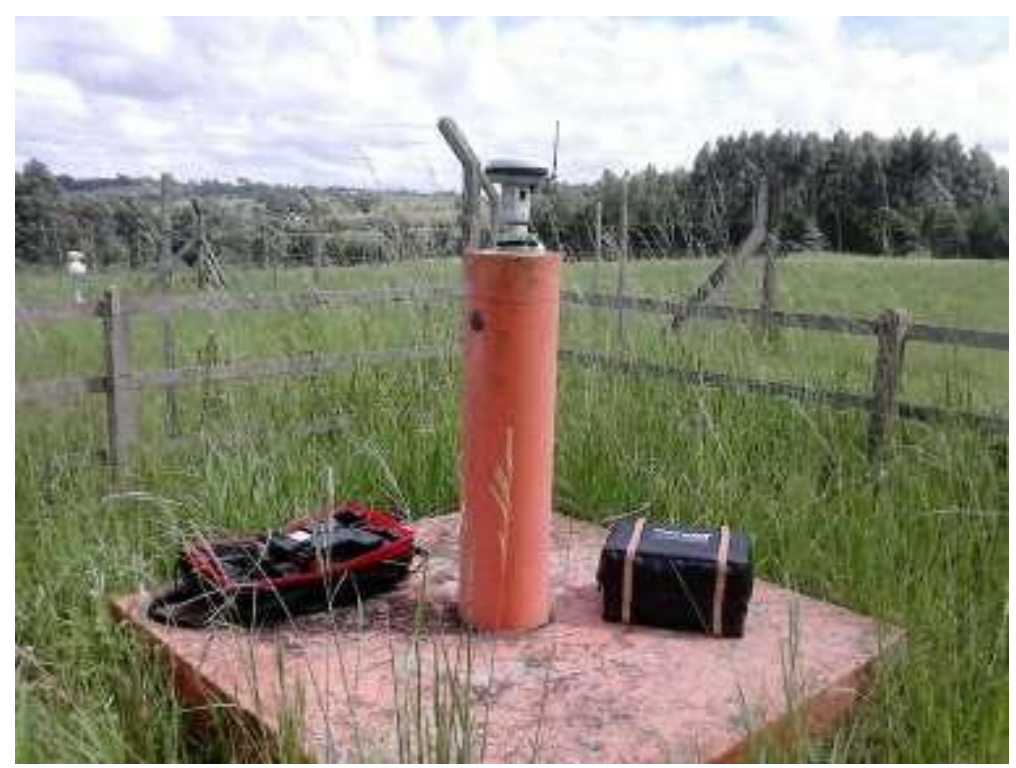

LATIN AMERICAN LATIN AMERICAN

Figura 1: Base receptora de dupla frequência (L1/L2), marca e modelo Leica Viva GS15. O instrumento está instalado sobre o Marco Geodésico de Segunda Ordem, no Câmpus da URI Santiago. Imagem referente a uma das cinco sessões de rastreio, em que o instrumento recebe sinas dos satélites das constelações GPS e GLONAS.

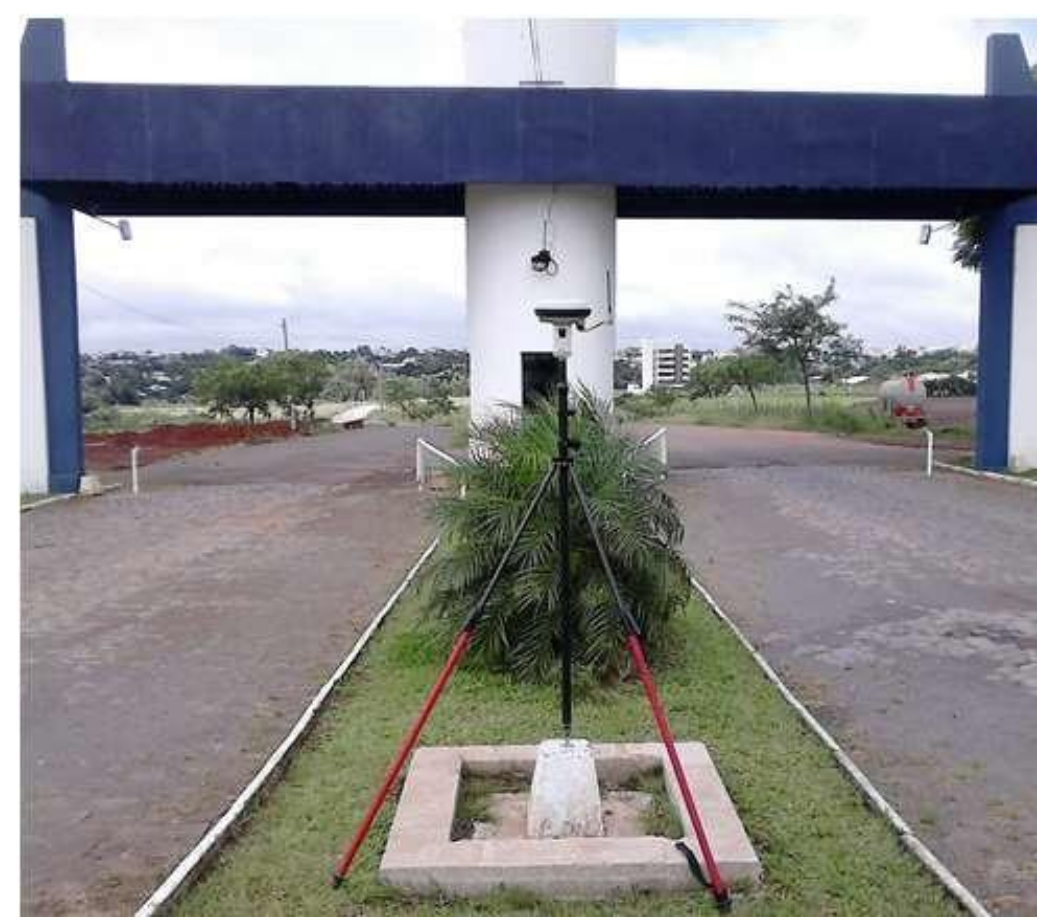

Figura 2: Marco de apoio nas cinco sessões de rastreio. Sobre o mesmo, o receptor móvel recebe os sinais dos satélites, em modo estático.

\subsection{RESULTADOS DO POSICIONAMENTO POR PONTO PRECISO (PPP) OBTIDOS}

\section{ATRAVÉS DAS SESSÕES DE LEITURAS}

Para os cálculos das coordenadas obtidas pelo processo do PPP e transporte foram utilizadas, como estação base fixa, durante os cinco processos de rastreio, os dados do rastreio do marco da URI Câmpus Santiago e da Base de Alegrete, RS, obtidos via Internet. 


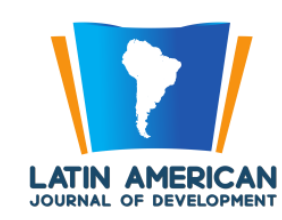

Para o marco de Santiago, na tomada de dados, empregou-se receptor GNSS fixo, de dupla frequência; e, para a base de Alegrete, foram utilizados os dados captados via Internet, no formato de arquivo RINEX, conforme disponibilizado para todas as estações bases da rede geodésica brasileira.

Os dados brutos resultantes de todas as sessões de rastreio foram processados no software Leica Geo Office, versão 8,3; onde foram gerados os resultados de diferenças lineares entre as coordenadas UTM SIRGAS/2000, calculadas pelo transporte do ponto do IBGE, do Câmpus de Santiago e pelo processo do Ponto Preciso (PPP), com dados da base de Alegrete.

\subsection{RESULTADOS DAS DIFERENÇAS LINEARES}

As tabelas 2 a 6 mostram os resultados das diferenças lineares entre os dois processos utilizados no rastreio.

Tabela 2: Diferença linear da posição do marco rastreado entre bases, observado no rastreio 1.

\begin{tabular}{|c|c|c|}
\hline \multicolumn{3}{|c|}{ Processo 1: 15/12/2014 } \\
\hline \multicolumn{3}{|c|}{ Duração: 4h39'51" } \\
\hline Processos & UTM SIRGAS 2.000 & Distancia (m) \\
\hline Base - Marco & $\begin{array}{ll}\text { E } & 705589,4420\end{array}$ & \multirow{4}{*}{242,3721} \\
\hline URI Santiago & 6768931,8400 & \\
\hline PPP Marco & 705647,4340 & \\
\hline Rastreado & 6768696,5080 & \\
\hline \multirow{2}{*}{ Base Alegrete } & 618997,0966 & \multirow{4}{*}{$108.192,1806$} \\
\hline & 6703910,1902 & \\
\hline PPP Marco & 705647,4340 & \\
\hline Rastreado & $\mathrm{N} \quad 6768696,5080$ & \\
\hline \multicolumn{2}{|c|}{$\begin{array}{l}\text { Diferença Linear do Marco } \\
\text { Rastreado entre Bases }(\mathrm{m})\end{array}$} & 0,0000 \\
\hline
\end{tabular}

Tabela 3: Diferença linear da posição do marco rastreado entre bases, observado no rastreio 2 ..

\begin{tabular}{|c|c|c|}
\hline \multicolumn{3}{|c|}{ Processo 2: 02/03/2015 } \\
\hline \multicolumn{3}{|c|}{ Duração: 2h26'09" } \\
\hline Processos & UTM SIRGAS 2.000 & Distancia (m) \\
\hline Base - Marco & E 705589,43700 & \multirow{4}{*}{242,3842} \\
\hline URI Santiago & N 6768931,83400 & \\
\hline PPP Marco & E 705647,43100 & \\
\hline Rastreado & N 6768696,49000 & \\
\hline & E $\quad 618997,09660$ & \multirow{4}{*}{$108.192,1675$} \\
\hline Base Alegrete & N 6703910,19010 & \\
\hline PPP Marco & E 705647,43100 & \\
\hline Rastreado & N 6768696,49000 & \\
\hline \multicolumn{2}{|c|}{$\begin{array}{l}\text { Diferença Linear do Marco } \\
\text { Rastreado entre Bases }(\mathrm{m})\end{array}$} & 0,0000 \\
\hline
\end{tabular}


Tabela 4: Diferença linear da posição do marco rastreado entre bases, observado no rastreio 3.

\begin{tabular}{|c|c|c|}
\hline \multicolumn{3}{|c|}{ Processo 3: 04/12/2015 } \\
\hline \multicolumn{3}{|c|}{ Duraçäo: 1h39'16" } \\
\hline Processos & UTM SIRGAS 2.000 & Distancia $(\mathrm{m})$ \\
\hline Base - Marco & E $\quad 705589,4690$ & \multirow{4}{*}{242,3774} \\
\hline URI Santiago & 6768931,8310 & \\
\hline PPP Marco & 705647,4550 & \\
\hline Rastreado & 6768696,4920 & \\
\hline \multirow{2}{*}{ Base Alegrete } & $\begin{array}{ll}\text { E } & 618997,0966\end{array}$ & \multirow{4}{*}{$108.192,1960$} \\
\hline & 6703910,1902 & \\
\hline PPP Marco & 705647,4524 & \\
\hline Rastreado & 6768696,5091 & \\
\hline $\begin{array}{l}\text { Diferença } \\
\text { Rastreado }\end{array}$ & $\begin{array}{l}\text { Linear do Marco } \\
\text { entre Bases ( } m \text { ) }\end{array}$ & 0,0173 \\
\hline
\end{tabular}

Tabela 5: Diferença linear da posição do marco rastreado entre bases, observado no rastreio 4 .

\begin{tabular}{|c|c|c|}
\hline \multicolumn{3}{|c|}{$\begin{array}{l}\text { Processo 4: } 09 / 03 / 2015 \\
\text { Duraçäo: } 2 \mathrm{~h} 34^{\prime} 30^{\prime \prime}\end{array}$} \\
\hline Processos & UTM SIRGAS 2.000 & Distancia (m) \\
\hline Base - Marco & E $\quad 705589,4310$ & \multirow{4}{*}{242,3738} \\
\hline URI Santiago & 6768931,8340 & \\
\hline PPP Marco & 705647,4060 & \\
\hline Rastreado & 6768696,4960 & \\
\hline \multirow{2}{*}{ Base Alegrete } & 618997,0966 & \multirow{4}{*}{$108.192,1511$} \\
\hline & 6703910,1901 & \\
\hline PPP Marco & 705647,4060 & \\
\hline Rastreado & 6768696,4960 & \\
\hline $\begin{array}{r}\text { Diferenç } \\
\text { Rastread } \\
\end{array}$ & $\begin{array}{l}\text { inear do Marco } \\
\text { entre Bases }(m)\end{array}$ & 0,0000 \\
\hline
\end{tabular}

Tabela 6: Diferença linear da posição do marco rastreado entre bases, observado no rastreio 5 .

\begin{tabular}{|c|c|c|}
\hline \multicolumn{3}{|c|}{ Processo 5: 23/03/2015 } \\
\hline \multicolumn{3}{|c|}{ Duração: 1h44'02" } \\
\hline Processos & UTM SIRGAS 2.000 & Distancia $(\mathrm{m})$ \\
\hline Base - Marco & $\begin{array}{ll}\text { E } & 705589,4310\end{array}$ & \multirow{4}{*}{242,3738} \\
\hline URI Santiago & 6768931,8340 & \\
\hline PPP Marco & E $\quad 705647,4060$ & \\
\hline Rastreado & 6768696,4960 & \\
\hline \multirow{2}{*}{ Base Alegrete } & 618997,0966 & \multirow{4}{*}{$108.192,1511$} \\
\hline & 6703910,1901 & \\
\hline PPP Marco & 705647,4060 & \\
\hline Rastreado & 6768696,4960 & \\
\hline $\begin{array}{l}\text { Diferenç } \\
\text { Rastread }\end{array}$ & $\begin{array}{l}\text { Linear do Marco } \\
\text { entre Bases }(m)\end{array}$ & 0,0000 \\
\hline
\end{tabular}


Tabela 7: Médias das diferenças lineares entre os processos.

\begin{tabular}{lc}
\hline \multicolumn{2}{c}{ Média das Diferenças de Distâncias dos 5 Processos } \\
\hline Processos & Média das Leituras $(\mathrm{m})$ \\
\hline Base Marco URI Santiago - PPP Marco Rastreado $(\mathrm{m})$ & 0,0273 \\
\hline Base Alegrete - PPP Marco Rastreado $(\mathrm{m})$ & 0,0160 \\
\hline
\end{tabular}

A tabela 4 informa que apenas o terceiro rastreio apresentou uma diferença linear de 0,0173 metros, referente às coordenadas do ponto rastreado com as bases da URI e de Alegrete, sendo que as demais leituras não apresentaram variabilidade. Esta diferença pode ser atribuída ao tempo de 1h39'16" de leitura desse rastreio, tempo menor, se comparado aos demais.

No entanto, os resultados das médias de diferença de distâncias expressos na tabela 07 estão em consonância com as determinações da Norma Técnica de Georreferenciamento de Imóveis Rurais

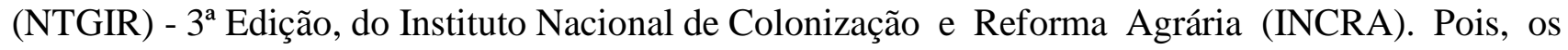
padrões requeridos para as diferentes precisões dos limites definidores da parcela, em cada imóvel rural, deverão obedecer aos seguintes critérios:

- para limites artificiais - melhor ou igual a 0,50 m;

- para limites naturais - melhor ou igual a 3,00 m;

- para limites inacessíveis - melhor ou igual a 7,00 m.

O estudo conclui que a maior diferença linear apresentada (0,0173 metros) entre as coordenadas UTM SIRGAS/2000, do ponto de apoio, obtidas pelos dois processos de rastreamento, atendem às diretrizes estabelecidas pela Terceira Norma Técnica de Georreferenciamento de Imóveis Rurais, em vigor, que é de 0,50 metros.

\section{MATÉRIAS ENCAMINHADAS PARA PUBLICAÇÃO}

Os resultados finais do presente trabalho serão encaminhados à submissão, em forma de artigo, nos próximos trinta dias, à Revista Eletrônica de Extensão da URI - Revista Vivências. Também, serão apresentados no XXI Seminário Institucional de Iniciação Científica (XXI SIIC), a realizar-se em Outubro próximo, na URI Câmpus de Santo Ângelo, RS, assim como outros congressos e seminários relevantes.

\section{OUTRAS ATIVIDADES DE INTERESSE UNIVERSITÁRIO}

\subsection{ATIVIDADES DE EXTENSÃO}

- Projetos em Andamento: "Sistema de Cadastro de Informação Mortuárias e de Localização Espacial de Jazigos Perpétuos opensuarce para o Cemitério Municipal da Cidade de Santiago”. 
- "Desenvolvimento e Implantação Piloto de um SIG Municipal Coorporativo, para o Apoio do Desenvolvimento Regional Sustentável”.

- Semana acadêmica de Arquitetura e Urbanismo (Abril/2014).

\subsection{ESTÁGIOS DE TREINAMENTO}

- Vaz Arquitetura e Engenharia

Período: 01/10/14 - 18/12/15

Função: Elaboração de Projetos em AutoCAD, SketchUp, Acompanhamento em obras, medições de terreno.

- Madalosso Projetos e Consultoria Ambiental LTDA

Período: 18/11/13 - 19/03/2014

Função: Elaboração de Projetos em AutoCAD, SketchUp, Acompanhamento em obras, Medições de Terreno.

\subsection{RESPONSABILIDADE SOCIAL}

Estágio - Concretize Ateliê de Arquitetura

Período: $\quad 01 / 04 / 15$

01/05/15

Função: Elaboração de Projetos em AutoCAD, SketchUp, Levantamentos.

\subsection{VIAGENS TÉCNICAS}

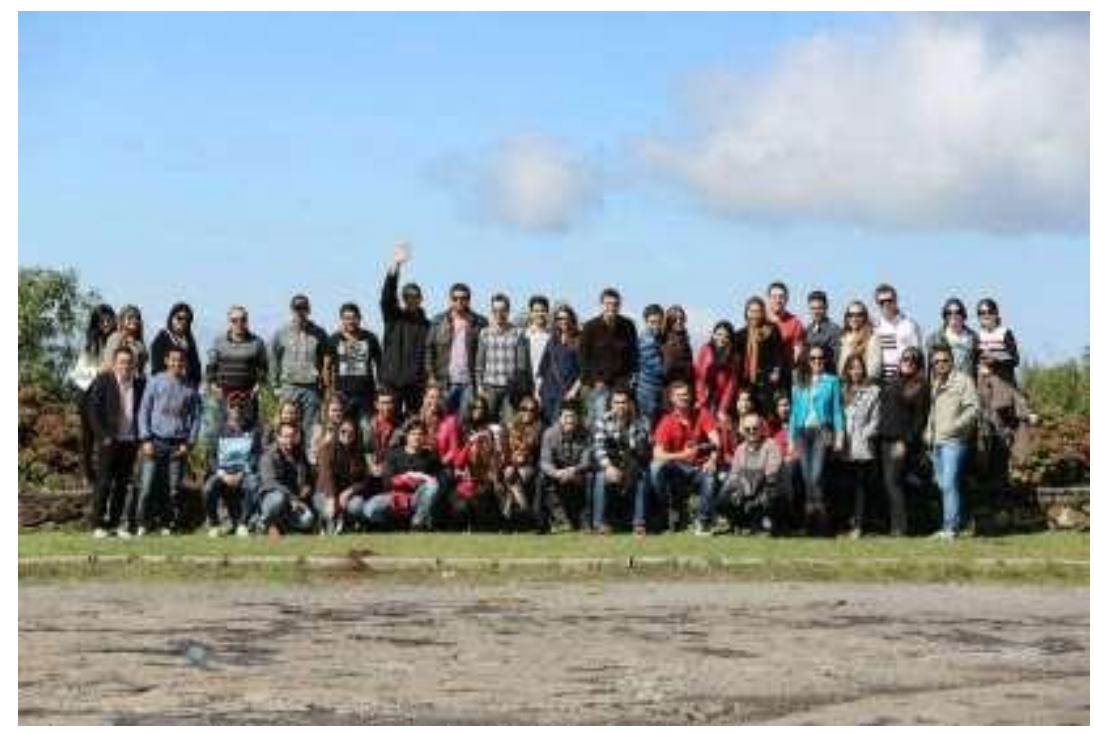

Figura 3: Gramado/Canela/Nova Petrópolis- RS (Março/2013). 


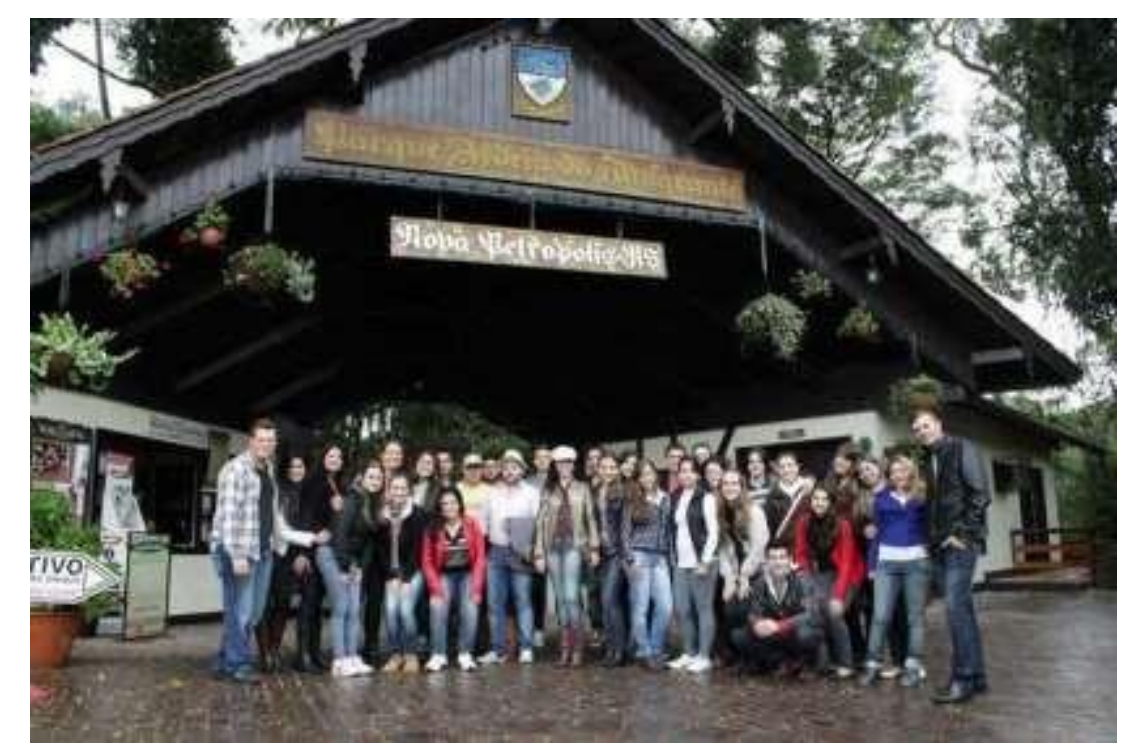

Figura 4: Condomínio Laje de Pedra.

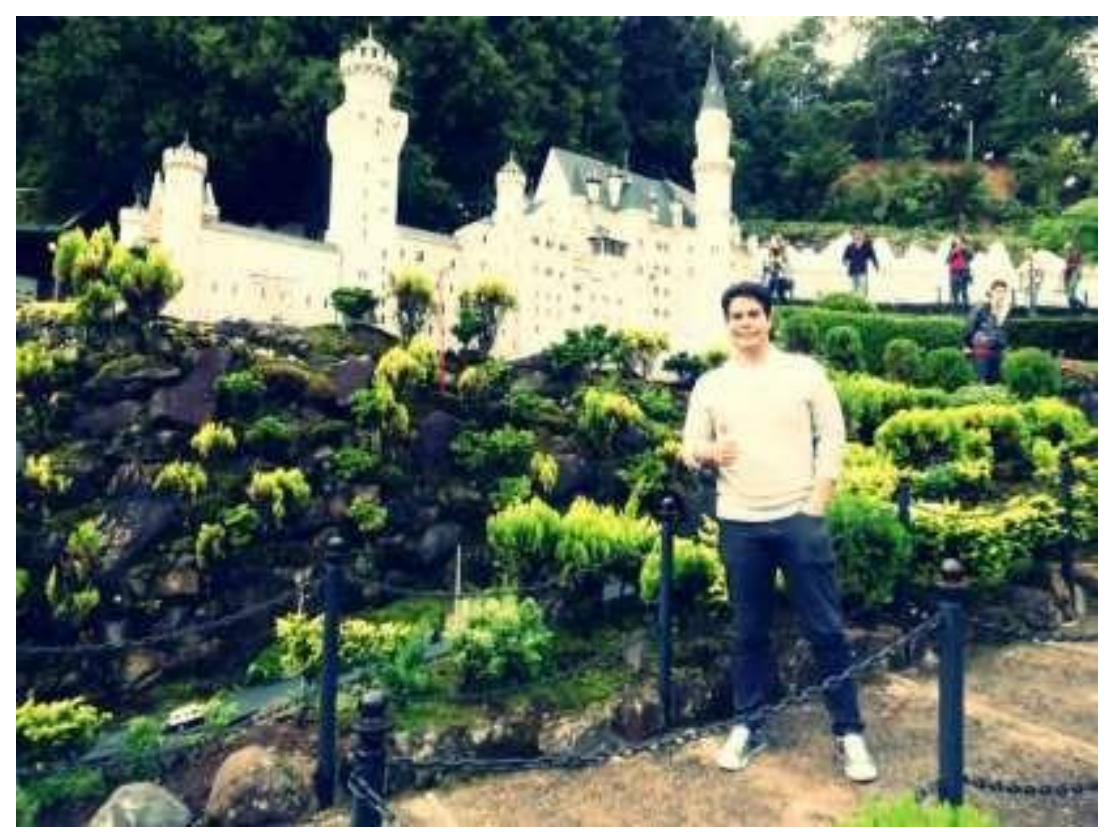

Figura 5: Parque Aldeia do Imigrante - Mini Mundo. 


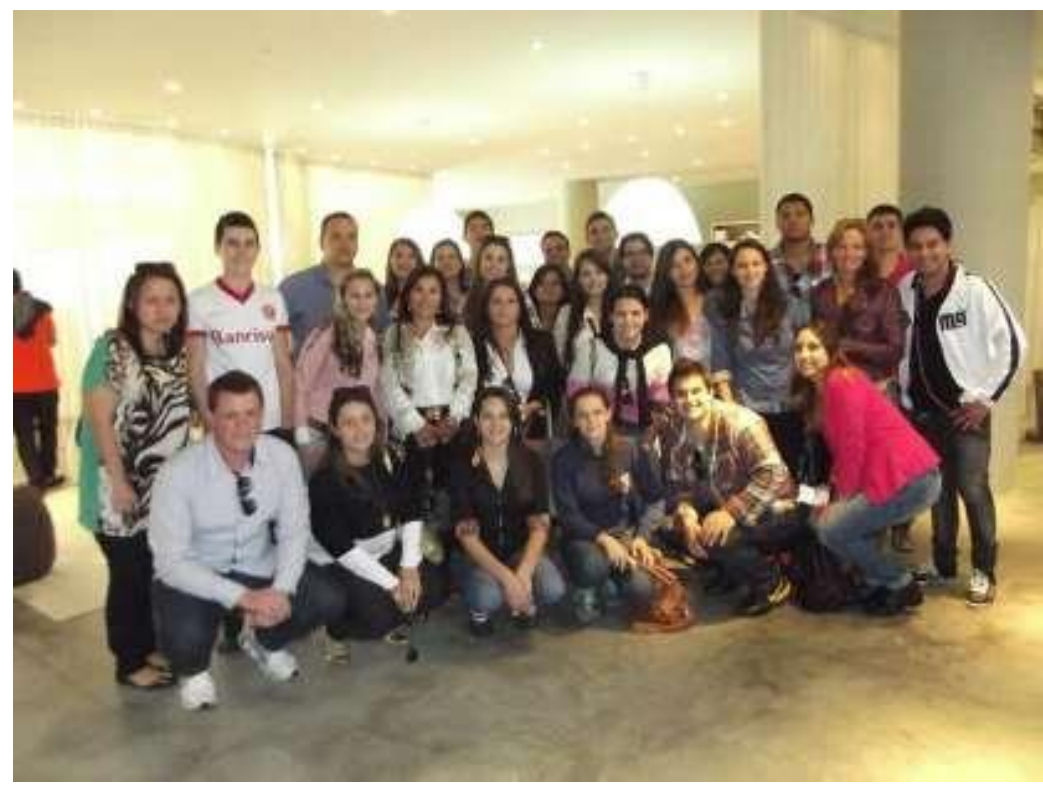

Figura 6: Bento Gonçalves - RS (Março/2014).

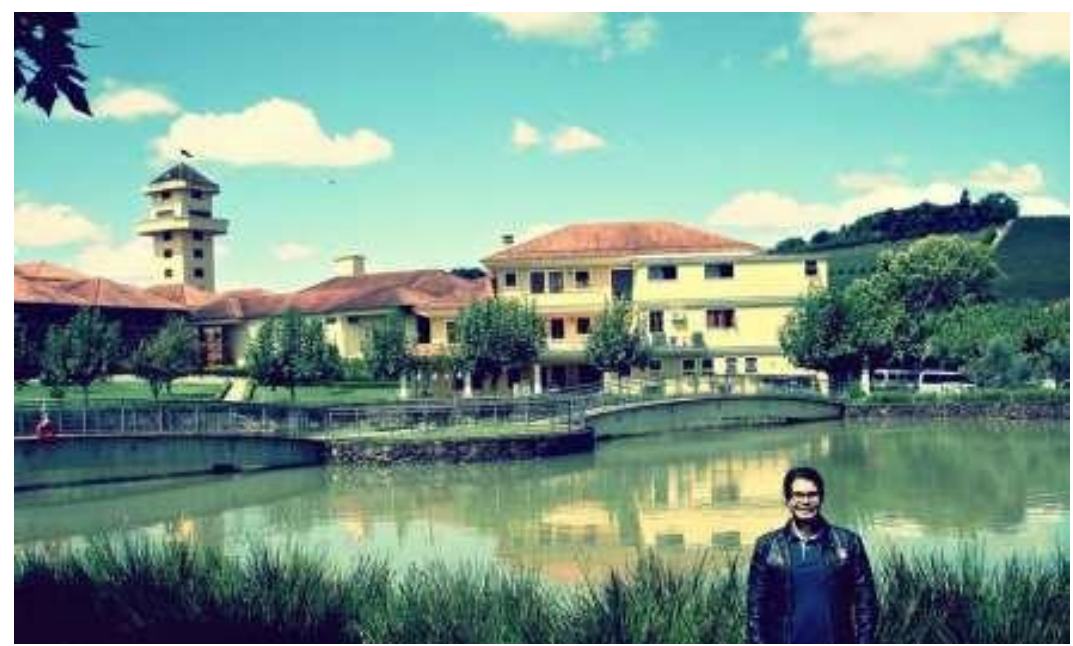

Figura 7: Vinícola Miolo.

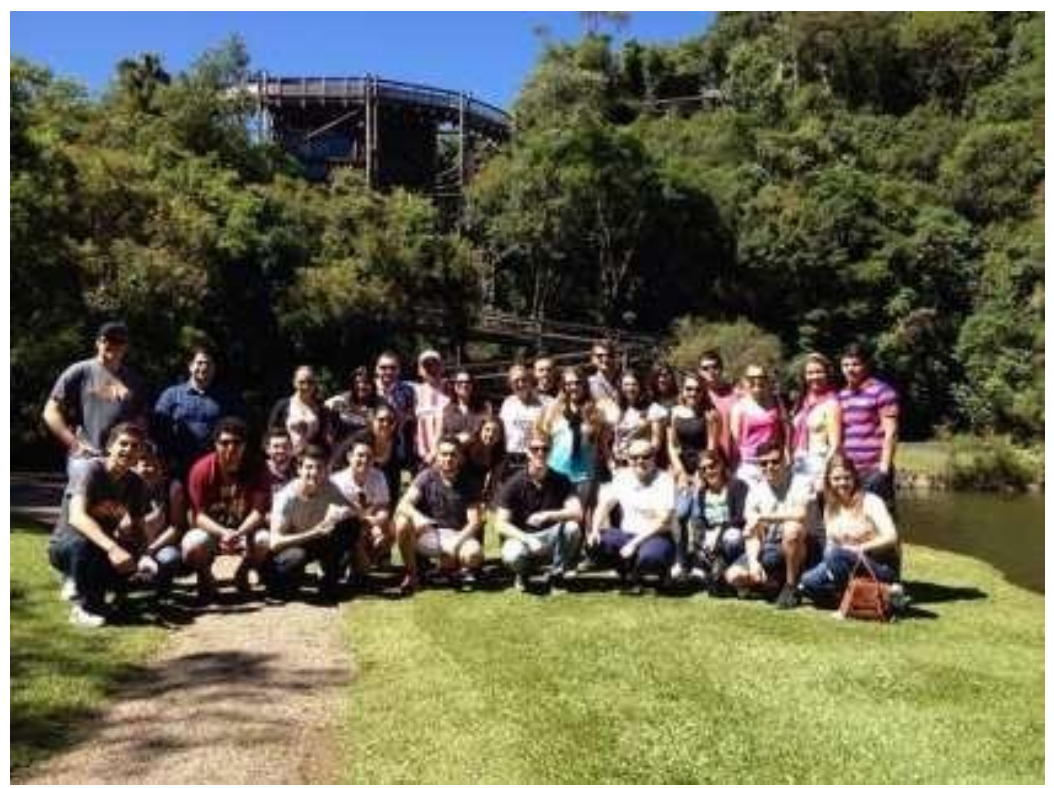

Figura 8: Unilivre 


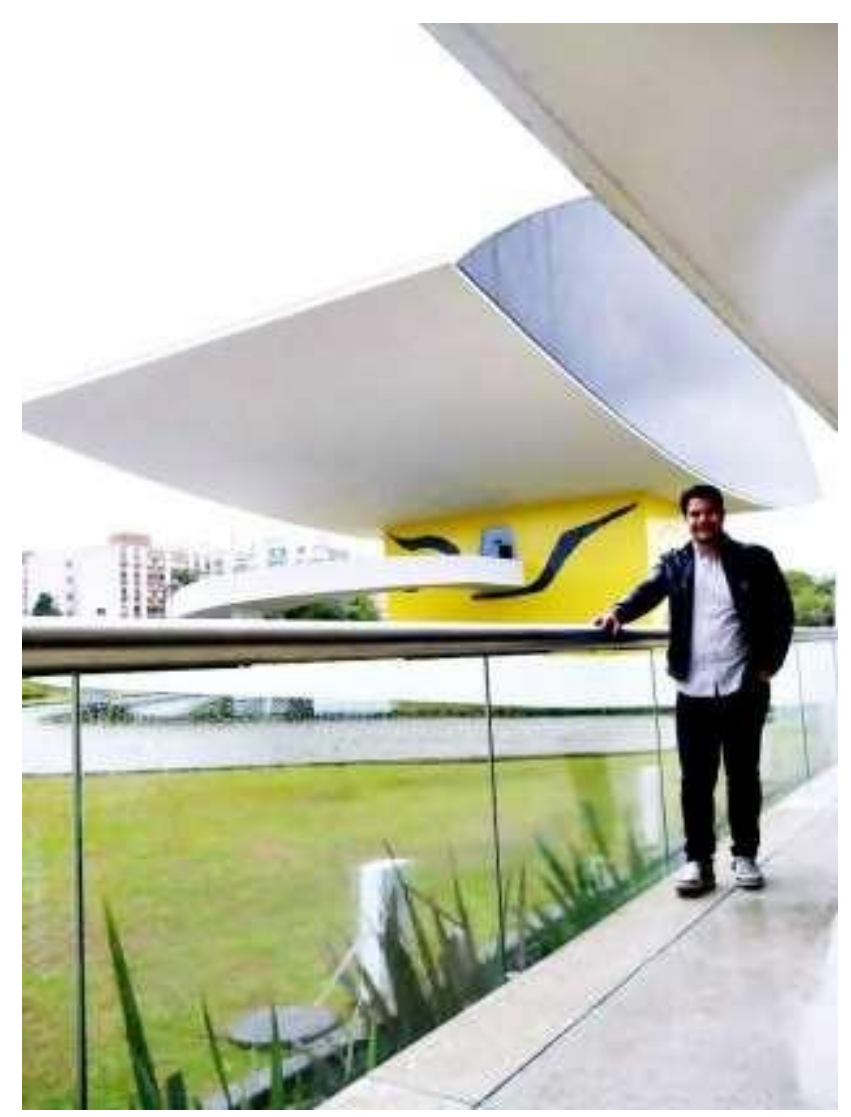

Figura 9: Museu Oscar Niemeyer.

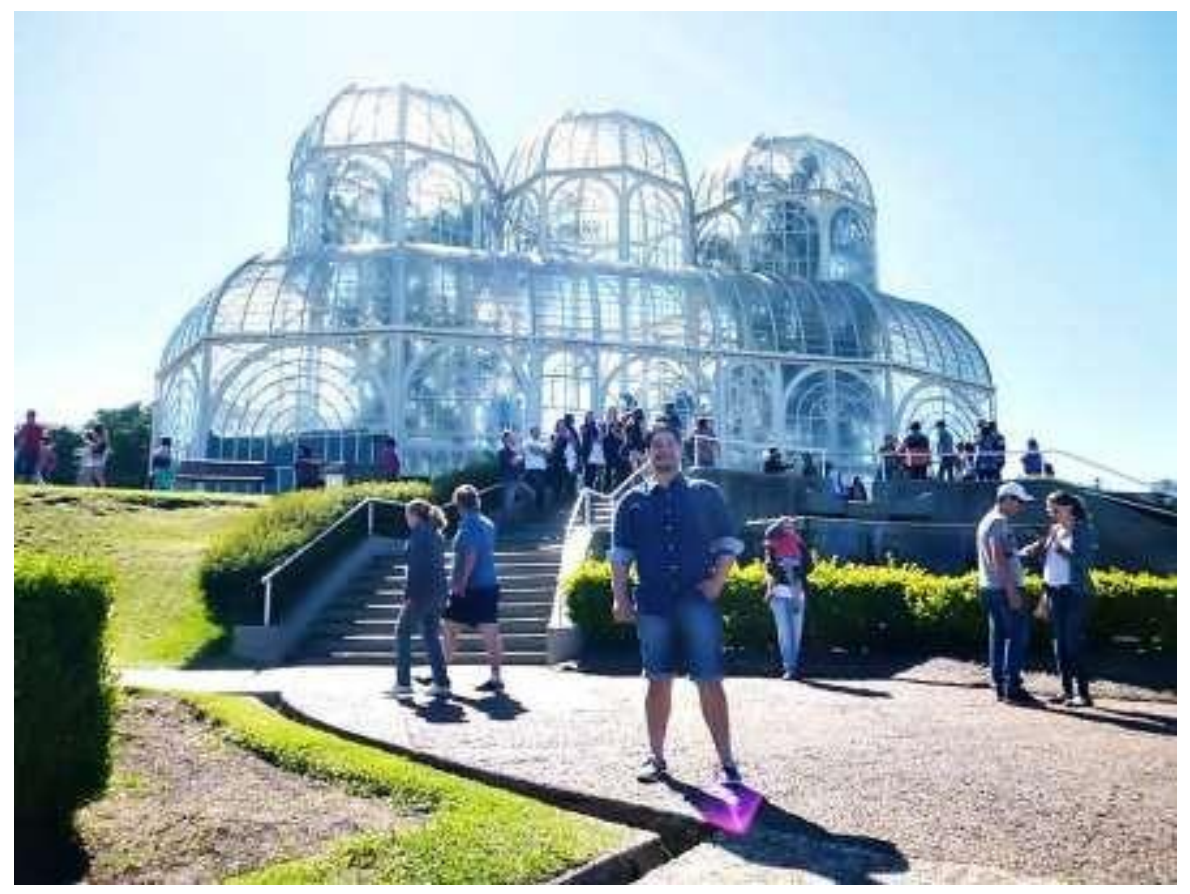

Figura 10: Jardim Botânico - Curitiba, PR (Novembro/2014). 


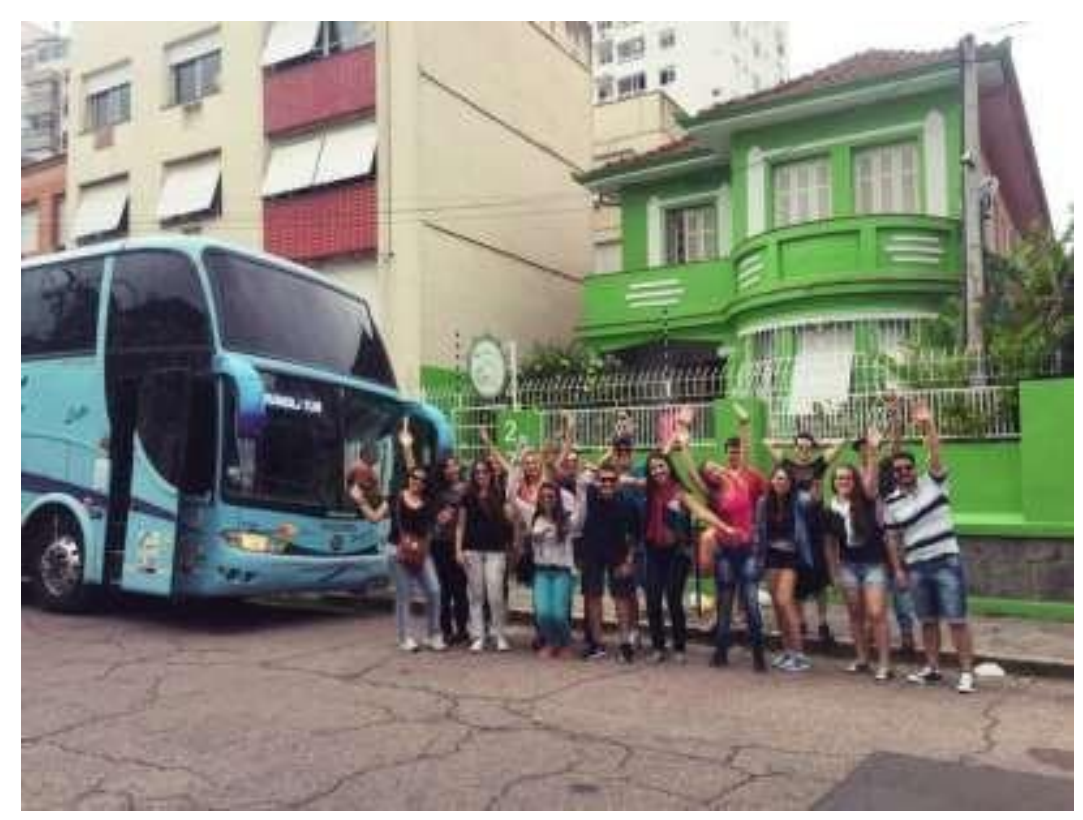

Figura 11: ECO HOSTEL Porto Alegre - RS (Março/2015).

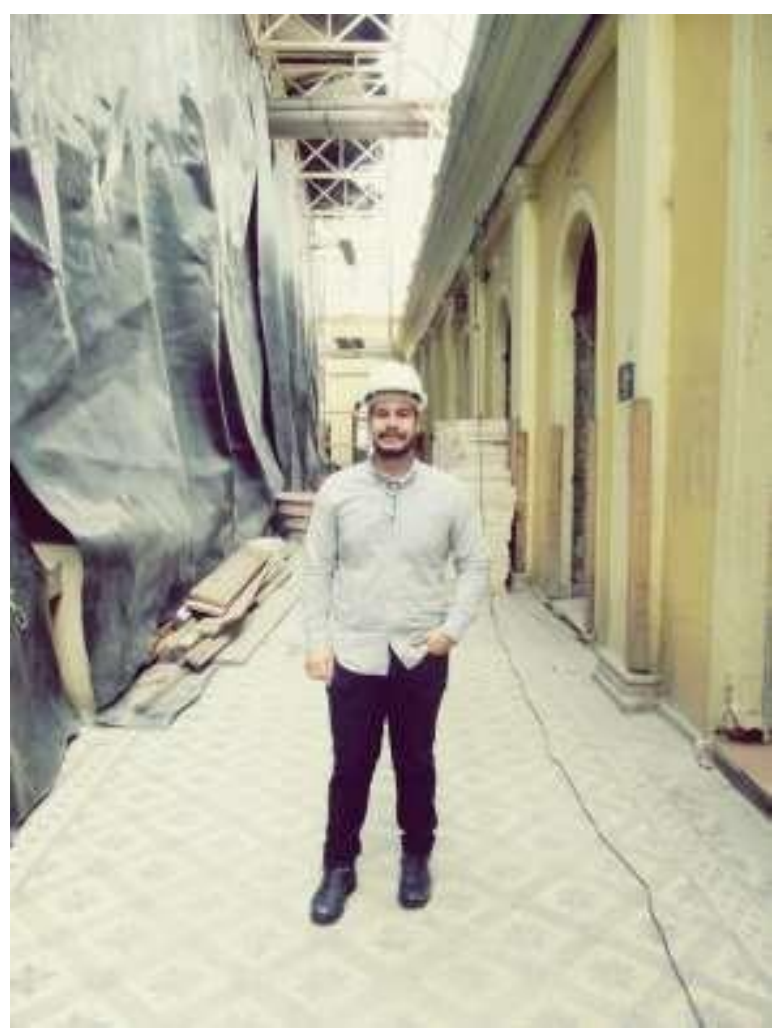

Figura 12: Restauração Mercado Público. 


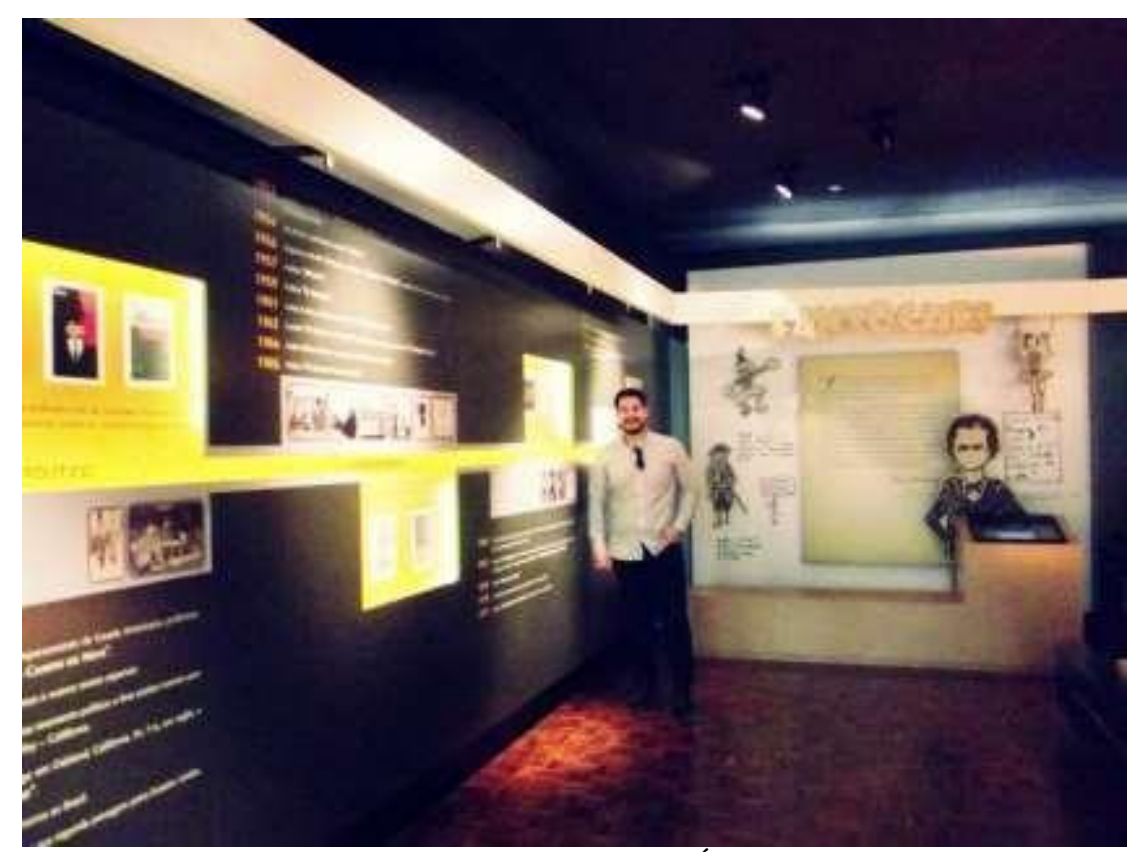

Figura 13: Centro Cultural CEEE Érico Veríssimo.

\section{PERSPECTIVAS DE CONTINUIDADE OU DESDOBRAMENTO DO PROJETO}

Como a URI é uma Universidade Comunitária e presta, eventualmente, serviços de extensão às prefeituras e demais entidades públicas, o Laboratório de Topografia e Geodésia da URI-Santiago, poderia disponibilizar um serviço de implantação de Marcos de Referencia, em locais onde tais entidades poderão desenvolver trabalhos de levantamentos topográficos de precisão, tais como cadastros; e, mesmo execução de levantamentos planialtimétricos para implantação de obras públicas que beneficiarão às comunidades. 


\section{REFERÊNCIAS BIBLIOGRÁFICAS \\ REFERENCIAS BIBLIOGRATICAS}

MONICO, João Francisco Galera. Posicionamento pelo GNSS: Descrição, Fundamentos e Aplicações. 2ed - São Paulo. Editora UNESP, 2008.

SEGANTINE, Paulo César Lima. GPS: Sistema de Posicionamento Global. São Carlos SP EESQ/USPU - 2005.

Norma Técnica para Georreferenciamento de Imóveis Rurais, INCRA $3^{\text {a }}$ Edição. Brasília 2013.

Manual Técnico de Posicionamento e Georreferenciamento de Imóveis Rurais. INCRA $1^{\text {a }}$ Edição. Brasília 2013.

Manual Técnico de Limites e Confrontações e Georreferenciamento de Imóveis Rurais. INCRA 1ª Edição. Brasília 2013.

Manual Técnico de Posicionamento e Georreferenciamento de Imóveis Rurais. INCRA $1^{\text {a }}$ Edição. Brasília 2013. 